Who is agile? An investigation of the psychological antecedents of workforce agility

Word count

6253 Words 


\begin{abstract}
Purpose. The aim of the present research was to investigate stable psychological traits of workers that are predictive of agility in order to build and validate an inventory to measure the potential for agility of workers.

Design/methodology/approach. First, in a qualitative study, we interviewed 11 professionals to identify core dimensions of workforce agility and psychological traits that support each dimension. Second, with a quantitative study, we tested on a sample of 808 workers the psychometric properties of an inventory - the agility index - measuring the traits identified in the first study.
\end{abstract}

Findings. Our qualitative study suggested a set of traits that contribute to workforce agility. Our agility index was found to capture adequately the set of traits - job-related curiosity, active listening, ambiguity tolerance, learning from past mistakes, anticipation and planning, job self-efficacy, risk-taking, and trust - and to predict workforce agility. Research implications. Despite its limitations, the current research sheds light on some important psychological antecedents of workforce agility, which improves our understanding of the workforce agility construct.

Practical implications. Managers could use our findings to assess the individual potential for agility when recruiting, training, or guiding employees.

Originality/value. In comparison with previous research, our study provides a more precise description of the psychological traits of workers that are associated with agility. Keywords: Workforce agility, Psychological traits, Inventory 
Who is agile? An investigation of the psychological antecedents of workforce agility

In a world changing rapidly, companies have to be agile rather than rigid to survive (Breu, Christopher, Strathern Hemingway, \& Bridger, 2001). At the level of a company, agility can be defined as the ability to adapt quickly to a variety of sudden evolutions in markets, technological tools, legal constraints, etc. (Breu et al., 2001). Goldman and Nagel (1993) have listed a series of factors that contribute to the agility of a company, including workforce agility. Like agile companies, agile workers are able to adapt to sudden changes, but also to take advantage of such changes (Chonko \& Jones, 2005). Workforce agility is a desirable characteristics as it has been shown to be a predictor of a work project's success (Sheffield \& Lemetayer, 2013) and firm performance (Khan \& Wisner, 2019). Consequently, being able to detect the potential for agility among workers - when selecting candidates or when assessing needs in training among employees - seems to be a promising endeavour.

Surprisingly, few empirical studies have investigated the psychological antecedents of workforce agility. Knowing more about the cognitive, conative, and emotional antecedents of workforce agility would be very valuable in order to be able to detect and support the potential for agility among workers. With the current study, we aim at addressing this important gap by theorizing more specifically about the conative antecedents of workforce agility. In two empirical studies, using qualitative and quantitative methods, we 1) identify a set of potential conative antecedents of workforce agility, 2) develop an inventory that assesses these antecedents, and 3) test the extent to which the measured antecedents are actually predictive of workforce agility.

\section{Workforce agility}

The first studies on workforce agility came from the observation that an important resource contributing to the agility of a company is the agility of its workforce (Goldman \& Nagel, 1993; Breu et al., 2001). Researchers then addressed the question and proposed various theoretical descriptions of workforce agility (Plonka, 1997; Breu et al., 2001; 
Muduli \& Muduli, 2016). Agile workers are described as fast in processing information, as adaptive more than reactive in turbulent work environments, and as motivated by self-development opportunities (Breu et al., 2001; Plonka, 1997). An agile workforce is often characterized as being open to changes and proactive when it comes to implementing changes (Plonka, 1997). In the same vein, workforce agility is related to openness to adopting different roles and accepting different levels of responsibility depending on the requirements of a project (Muduli \& Muduli, 2016). Another important characteristic of an agile workforce according to researchers is its tendency to value cooperation and information sharing (Breu et al., 2001).

Companies aiming at agility need to understand how to foster their workforce agility (Breu et al., 2001). Several researchers have focused on the organizational factors that can contribute to workforce agility (e.g., Alavi, Abd. Wahab, Muhamad, \& Arbab Shirani, 2014; Doeze Jager-van Vliet, Born, \& van der Molen, 2019). They have shown, for example, that the implementation of agile strategies, the organization of work, the implementation of various policies such as salary-skill-based pay improvement incentives, or the support for power sharing are all factors that positively contribute to the development of workforce agility (Alavi et al., 2014). Recent research also suggests that providing employees with agile goals and tools to monitor the achievement of such goals facilitates agility (Doeze Jager-van Vliet et al., 2019). Beyond organizational levers, companies could try to use dispositional levers to strengthen the agility of their workforce. For example, companies could recruit individuals with high potential for agility. They could also work on detecting the potential of employees in order to support and develop it among employees who need it the most. For such actions to be implemented, it is crucial to be able to detect an individual's potential for agility - that is, characteristics of workers that support agility. Surprisingly, there has been until now very little research on the psychological factors that are associated with workforce agility (Sheffield \& Lemetayer, 2013; Muduli, 2017). 


\section{Conative antecedents of workforce agility}

The potential for agility is arguably multifactorial (Sheffield \& Lemetayer, 2013). Regarding psychological factors, we believe that it involves cognitive factors, conative factors, as well as emotional factors. Conative factors - that is, personality traits, behavioral tendencies, motivations - are of particular interest because they can be assessed quickly when recruiting an individual, or as part of the continuous assessment of employees. In the present section, we argue that several conative factors might be particularly relevant when predicting workforce agility.

Previous research on the psychological antecedents of workforce agility has adopted an undifferentiated approach to the psychological constructs involved in agility. For example, Muduli (2017) has studied the link between psychological empowerment - which is a mixture of several conative factors such as job self-efficacy or self-determination - and workforce agility. The results of Muduli (2017) show that there is a positive link between psychological empowerment and workforce agility. However, this research has several limitations. First of all, it does not make it possible to determine to what extent each dimension of psychological empowerment is linked to workforce agility. This limits the finesse of the theoretical understanding of the predictive factors of workforce agility and thus limits the practical relevance of the study. In addition, the study by Muduli (2017) omits a number of conative factors that could be predictors of workforce agility. In the present section, we aim at introducing a series of conative factors that could contribute to workforce agility.

Several definitions of workforce agility emphasize the necessity of being open to different roles and changes in order to be agile (Muduli \& Muduli, 2016, 2016). Curiosity, which can be defined as a drive for acquiring new knowledge and sensory experiences (Berlyne, 1978; Loewenstein, 1994), could play an important supporting role for workforce agility. Curiosity tends indeed to drive exploratory behavior (Loewenstein, 1994). Work-related curiosity is the specific form of curiosity related to work (Mussel, Spengler, 
Litman, \& Schuler, 2012; Mussel, 2013). Previous research has shown that workers with high levels of work-related curiosity tend to be more open to changes and proactive when it comes to implementing changes as it is a positive predictor of innovative behaviors (Çelik, Storme, Davila, \& Myszkowski, 2016). As being open to changes is an important aspect of workforce agility according to Plonka (1997), work-related curiosity could foster agility, especially when it comes to searching for information, by facilitating attitudes such as active listening and learning from past errors.

The definition of workforce agility also emphasizes the complexity and the ambiguity of the environments in which workforce agility is required (Breu et al., 2001; Plonka, 1997). In environments requiring agility, the information that workers have to deal with is usually complex and ambiguous (Sheffield \& Lemetayer, 2013). We could therefore expect that tolerance for ambiguity is an important resource to deal with informational complexity. Ambiguity tolerance can be described as the ease with which individuals perceive, evaluate and respond to ambiguous stimuli (Budner, 1962). Budner (1962) described three sources of informational ambiguity in his original conceptualization of ambiguity tolerance: unfamiliarity, complexity, and inconsistency of information. Such situations are frequent in environments requiring agility (Sheffield \& Lemetayer, 2013), hence the possible importance of being tolerant for ambiguity to be agile when making decisions in work-related or career-related tasks (Westerberg, Singh, \& Häckner, 1997; Storme, Celik, \& Myszkowski, 2019).

Another important aspect of workforce agility that is emphasized in some definitions is the necessity to cooperate, by, for example, sharing information with co-workers, supporting co-workers in their tasks and activities, etc. (Breu et al., 2001). Trust has been shown to be a prerequisite for cooperation. Research indeed shows that information sharing and cooperation are facilitated when collaborators trust each other (Butler Jr, 1999). Cooperation and its prerequisites can be expected to be an important resource for workforce agility according to these definitions. 
There are additional resources that are not emphasized in the definitions of workforce agility but that could nevertheless be considered as important antecedents of workforce agility. Implementing solutions in changing environments can be risky and has to be well planned to a certain extent. To adapt to turbulent environments, companies and their workforce sometimes have to take actions that are radically new and that might have unknown consequences (Sheffield \& Lemetayer, 2013). An agile workforce should therefore be able to take a certain amount of risk in their activities (Sheffield \& Lemetayer, 2013). We hypothesize that the tendency to take risks at work could support workforce agility.

Making risky decisions also requires from workers to be self-efficacious (Krueger Jr \& Dickson, 1994). The concept of self-efficacy is central in Bandura's General Social Cognitive Theory (1977). It can be defined as the confidence one has in his/her own capacities. Self-efficacy beliefs are influenced by sources of efficacy information as well as personality and contextual factors. Self-efficacy beliefs have been shown to predict adaptive behaviors in various domains such as entrepreneurial decision-making (Fuller, Liu, Bajaba, Marler, \& Pratt, 2018) or career decision-making (Storme \& Celik, 2018). Job self-efficacy has been shown to be positively associated with persistence and coping (Sherer et al., 1982; Schaubroeck \& Merritt, 1997), which are both important assets to adapt in turbulent environments. We can therefore expect that job self-efficacy is another important resource for workforce agility.

\section{Study overview}

In the present paper, we report the findings of two empirical studies that provide evidence for the role of several psychological traits as antecedents of workforce agility. Our aim with the first study was to interview professionals with relevant experience in order to understand better the core processes involved in workforce agility and the psychological resources that support these processes. Based on the interviews, we aimed in a second study at developing a psychometrically sound assessment tool to measure the hypothesized 
conative antecedents of workforce agility. We built first an item pool on the basis of the content of interviews. Then we tested the discrimination power, reliability, and construct validity of the newly built instrument on a sample of workers. It is important to note that our instrument - unlike existing instruments that measure workforce agility (Muduli, 2017; Liu, Li, Cai, et al., 2015) - is not intended to measure the respondent's actual workforce agility, but rather his/her psychological potential for agility.

\section{Study 1: Exploring the antecedents of workforce agility}

In this study, professionals who had experience with the notion of workforce agility were asked to share their ideas on what is expected from agile workers in terms of core dimensions, and on which psychological resources support each core dimension. The aim of the study was to propose a measurement model for the construction of an inventory tested in Study 2.

\section{Study 1: Method}

\section{Participants}

For this exploratory study, we interviewed 11 professionals from organizations who had experience with workforce agility. The professionals were selected by consultants specialized in workforce agility. Participants were senior executives, founders of start-ups, professionals with start-up support functions, or agility consultants. The gender ratio was approximately balanced in the sample (6 men and 5 women). All participants had at least five years of job experience in managerial positions. We continued sampling until we reached theoretical saturation (Bowen, 2008).

\section{Procedure}

We used a qualitative methodology to gather rich data in order to capture relevant antecedents that could not be derived satisfactorily from the scarce existing literature. The 
interview was semi-structured. We had an interview guide to help in conducting the interviews. Professionals were first invited to briefly introduce themselves and their relevant work experience. Then they were asked to define workforce agility and how workforce agility is an important issue for organizations. In a second step, professionals were asked to mention the psychological resources that they felt were important to support agility.

\section{Data coding and analysis}

We relied on the constant comparative method (Boeije, 2002) to analyze the content of interviews. This method consists in going from data to theory and back from theory to data in a constant interaction (Boeije, 2002). We transcribed the interviews and coded for 1) core dimensions of workforce agility, 2) resources that support each core dimension. These empirical observations were compared to available models in the literature and integrated conceptually.

\section{Study 1: Results}

\section{Core dimensions of workforce agility}

There is a relative consensus among the professionals that we interviewed on the definition of workforce agility. Workforce agility refers to the ability to adapt in an environment that changes very quickly and unpredictably. For some professionals, workforce agility differs from adaptation in that the latter does not require anticipation skills: "The main difference between agility and adaptation is that agility implies anticipation, whereas adaptation is just a reaction to a change".

The dimensions of workforce agility correspond to basic information processing and decision-making processes. The professionals that we interviewed described first the role of gathering information when being agile. The agile worker is able to collect relevant information, that is, information that allows him to anticipate and respond to changes. Once this information is collected, the agile worker is able to integrate this often complex 
and ambiguous information, make an appropriate decision, and plan an action. The implementation of this action is the last dimension of agility that is mentioned by our participants.

\section{Conative resources supporting workforce agility}

We then tried to identify the resources that play an important role in supporting each dimension (see Table 1 for a synthesis). A number of resources mentioned by professionals help agile individuals to gather information in their environment. These resources include curiosity and the tendency to listen with humility. The content of the interviews indicate that being willing to acquire new information is crucial for agility as it feeds the decision-making process.

Insert Table 1 about here

Curiosity refers to the motivation of an individual to gather new information. According to our participants, curiosity drives necessary exploratory behaviors among agile workers. This general notion of curiosity could be associated with another resource mentioned by professionals, namely humble active listening. What we refer to as "humble

active listening" is an individual's tendency to consider that external sources of information (e.g. other collaborators) may be superior to his or her own sources. Listening with humility is distinguished from empathy by its purpose, which is not so much to try to understand the other but to acquire information (Davis, 1983). It is possible in this sense that humble active listening is related to curiosity.

Professionals also mentioned resources related to information processing, which are learning from one's own mistakes and ambiguity tolerance (Furnham \& Marks, 2013). Learning from one's past mistakes is an important process contributing to continuous improvement. Ambiguity tolerance, as defined by the professionals that we interviewed, refers to the absence of discomfort when confronted with complex or ambiguous situations. 
More than an appetite for ambiguity, several participants insisted on the notion of the absence of negative affects caused by ambiguity among agile individuals.

Among the resources supporting decision making, participants often mentioned the importance of anticipating and planning, but also of feeling self-efficacious. Agile individuals are characterized by an ability to imagine several possible action plans to be able to bounce back in the event of failure. This dimension could be described as divergent planning and considered as a specific form of divergent thinking related to planning and anticipating actions. According to our participants, making decisions is also supported by job self-efficacy beliefs.

The analysis of the interviews revealed finally that taking action is supported by risk-taking and trust in others. According to participants, being able to take risks allows agile workers to create and test imperfect prototypes, which will allow them to accumulate valuable information for the continuous improvement of the product or service. When taking action, cooperation is necessary to convey the necessary information to others with whom agile workers collaborate - they may be clients or colleagues. According to professionals, the main pre-requisite for cooperation is to trust one's collaborators.

\section{Study 1: Discussion}

Study 1 allows us to hypothesize on the supporting role of a set of conative resources in workforce agility. The resources facilitate agility at different stages of the agile process. Being curious and listening actively with humility seem to be resources that support the process of gathering information. When processing information, tolerating ambiguity and learning from past mistakes are crucial resources. Making decisions requires anticipating and planning, as well feeling self-efficacious. Finally, taking action seems to require to take risks and to trust co-workers. 


\section{Study 2: Inventory development and validation}

The aim of Study 2 was to build and validate an inventory measuring the conative antecedents of workforce agility identified in Study 1. Note that there are already existing scales measuring some of the listed constructs, such as the work-related curiosity scale of Mussel (2013), or the job self-efficacy scale of Rigotti, Schyns, and Mohr (2008). However, these scales differ in length, type of response scales, and type of phrasing. In the present research, we decided to develop our own concise battery of questionnaires to maximize the standardization of the assessment across dimensions.

The aim of the second study was also to test the hypothesized relationships between the conative antecedents and workforce agility. We hypothesized that all constructs measured by the inventory developed in Study 2 would be positively related with workforce agility.

\section{Study 2: Method}

\section{Participants}

For the second study, we recruited 808 U.S. participants (349 females, $M_{\text {age }}=32.96$ years, ranging between 18 and 70 years old) via the Microworkers platform. Microworkers is an online labor market - comparable to Amazon Mturk - that allows researchers to recruit participants who complete online tasks in exchange for compensation. Microworkers allows accessing a more diverse pool of participants than snowballing techniques (Behrend, Sharek, Meade, \& Wiebe, 2011). Behrend et al. (2011) have shown that Microworkers' samples are comparable to the general population on a series of basic demographic characteristics. They also have shown by empirical studies that Microworkers provide results comparable to those obtained in paper-and-pencil studies (Behrend et al., 2011). We only recruited Microworkers participants with a job - employees or managers on the side of their Microworkers job. They were rewarded with $\$ 3.00$ for their participation.

Regarding the demographics, $59.90 \%$ of participants had college or university degrees. 
The sample included $21.66 \%$ of individuals with managerial positions. The average job experience was 12.94 years (ranging between 0 and 50 years). The average tenure in the current job was 4.94 years (ranging between 0 and 37 years). More than 150 different job titles were represented in the sample.

\section{Material}

\section{Conative antecedents of workforce agility inventory: the Agility Index.}

We used the content of interviews from Study 1 as a source of inspiration to create a pool of items tapping into various psychological traits relevant for workforce agility. We made sure that all items were phrased in a similar way to increase the consistency of the whole instrument. We generated 10 to 15 items per dimension and proceeded to select items based on 1) the distributions of participants' responses, and 2) factor loadings. We dropped items to which all participants tended to provide similar responses - that is items that do not discriminate respondents - and items with factor loadings that were less than .60. The final inventory consisted of 51 items measuring the eight hypothesized conative antecedents of workforce agility: curiosity (8 items; e.g., "I like to understand how things work"), humble active listening (6 items; e.g., "I am interested in listening to what others can teach me"), learning from past mistakes (6 items; e.g., "I feel I have learned a lot from my mistakes"), ambiguity tolerance (6 items; e.g., "I need information to be presented clearly to be comfortable" is a reversed item), risk-taking (6 items; e.g., "I am willing to invest my time in a project I believe in, even if it is risky"), anticipation and divergent planning (6 items; e.g., "Before embarking on a project, I try to consider several different action plans"), trust (6 items; e.g., "I do not suspect motives hidden in people with whom I work"), job self-efficacy (7 items; e.g., "I successfully complete my tasks at work"). All items were designed to be rated using a 5-point Likert scale from 1 ("strongly disagree") to 5 ("strongly agree"). 
Workforce agility scales. We used the 7-item measure of workforce agility developed and validated by Muduli (2017). The scale has been shown to have a satisfactory scale-score reliability and convergent/divergent validity (Muduli, 2017). Sample items are "I am comfortable with change, new ideas, and new technologies in my organization" and "I am flexible to quickly change from task to task, job to job, and place to place". Participants respond using a 5-point Likert scale from 1 ("strongly disagree") to 5 ("strongly agree"). The observed internal consistency in our sample was satisfactory with a Cronbach's $\alpha$ of .85 .

In addition, we used the 12-item measure of workforce agility developed and validated by Liu et al. (2015), which has also been shown to have a satisfactory scale-score reliability and convergent/divergent validity (Liu et al., 2015). Sample items are "I look for the opportunities to make improvements at work" and "I keep up-to-date at work". Participants respond using a 5-point Likert scale from 1 ("strongly disagree") to 5 ("strongly agree"). The observed internal consistency in our sample was satisfactory with a Cronbach's $\alpha$ of .86 .

\section{Procedure}

All participants took the survey online via the Microworkers platform. Participants first filled in the inventory measuring the antecedents of workforce agility, then took the two workforce agility scales, and then provided demographic information.

\section{Data analysis}

Based on item distribution analyses, we eliminated items that failed at discriminating respondents. We ran factor analyses on each subscale of the inventory and dropped items that had factor loadings smaller than .60. We then checked the validity of the factor structure with ordinal Confirmatory Factor Analysis (CFA, Schumacker \& Lomax, 2004; Rosseel, 2012). We compared three models. The main model assumed that the instrument consists of 8 correlated factors. The fit of the main model was also compared with the fit of 
a one-factor model, and with the fit of a model with 8 independent factors. To assess the absolute fit of models, we followed the recommendations of Schumacker and Lomax (2004) and used four statistical indices: The $\chi^{2} / d f$ ratio (should be $<5$ ), the Comparative Fit Index (CFI should be $>.90$ ), the Standardized Root Mean Square Residual (SRMR should be $<.08)$ and the Root Mean Square Error of Approximation (RMSEA should be < .09). The analysis was performed with the R package lavaan (Rosseel, 2012). We then investigated the relations between the conative factors measured by our inventory and validated measures of workforce agility.

\section{Study 2: Results}

Confirmatory Factor Analyses (CFA) were conducted to investigate the factor structure of the assessment. We compared three models. The main model assumed that the instrument consists of 8 correlated factors. The fit of the main model was also compared with the fit of a one-factor model, and with the fit of a model with 8 independent factors. As expected, we found that the absolute fit of the model with 8 correlated factors was satisfactory $\left(\chi^{2} / d f=3921.24 / 1196=3.28, \mathrm{CFI}=.92, \mathrm{RMSEA}=0.05, \mathrm{SRMR}=0.06\right)$. The one-factor model $\left(\chi^{2} / d f=14307.73 / 1224=11.68, \mathrm{CFI}=.61, \mathrm{RMSEA}=0.12\right.$, SRMR $=0.10)$ and the 8-independent-factor model $\left(\chi^{2} / d f=23065.95 / 1224=18.84, \mathrm{CFI}=.35\right.$, RMSEA $=0.15$, SRMR $=0.27)$ both had poor absolute fit.

We then computed Cronbach's $\alpha$ 's per dimension to investigate the reliability of the new instrument. All subscales exhibited satisfactory internal consistency with observed $\alpha$ 's of $.86, .83, .83, .82, .79, .86, .77$, and .84 for respectively work-related curiosity, active listening, ambiguity tolerance, learning from past mistakes, anticipation and planning, job self-efficacy, risk-taking, and trust in collaborators.

We then proceeded to explore the correlations between our instrument and two measures of workforce agility. Correlations are reported in Table 2. We found that each dimension of our instrument correlated positively with both scales of workforce agility. 
Insert Table 2 about here

\section{Study 2: Discussion}

We developed and tested the psychometric properties of an inventory - the Agility Index - measuring various hypothesized conative antecedents of workforce agility. Each subscale has similar number of items, phrasing, and response scales. Altogether, our findings revealed that the inventory has an appropriate factor structure that distinguishes adequately the different factors. Furthermore, our instrument exhibited satisfactory scale-score reliability. Consistent with our hypotheses, we found that each one of the conative antecedents of workforce agility was positively related with two different validated scales of workforce agility.

\section{General Discussion}

The aim of this research was to investigate the conative antecedents of workforce agility. To achieve this aim, we first interviewed professionals to explore the possible antecedents and then developed and validated an inventory - the Agility Index - measuring the antecedents. In line with our expectations, we found that all eight dispotional factors identified by the participants interviewed in Study 1 were positively related to workforce agility. It is however important that all factors are not equally strongly related to workforce agility. Our findings suggest, for example, that ambiguity tolerance is less strongly related to workforce agility than the other factors. In the same vein, the relationship between trust and workforce agility is less strong than the relationships between job-related curiosity or job self-efficacy and workforce agility. This suggests that some factors might be more important than others. By providing a detailed list of conative factors associated with workforce agility, the present research extends previous research on the psychological antecedents of workforce agility, which had adopted an undifferentiated approach to the psychological constructs involved in agility (Muduli, 2017). 


\section{Theoretical and practical implications}

Our results have important implications, both theoretical and practical. On the theoretical level, our study is the first one to show which psychological traits are associated with workforce agility. By introducing psychological traits into the prediction of workforce agility, our research helps reveal the multivariate nature of workforce agility, which was until now almost exclusively considered as influenced by organizational characteristics (Alavi et al., 2014). In doing so, our research contributes to improving the understanding and prediction of workforce agility.

The current research has two related implications for practice. First, our findings can help practitioners like recruiters and managers detect among job applicants those who have the strongest potential for workforce agility. Second, our findings can help managers to

define more specifically the content of training interventions aimed at fostering workforce agility. Job applicants with high scores on the dimensions that we idendified with our studies should be favored when workforce agility is desired. Training intervention designers could also focus on the conative antecedents identified in this research when trying to influence the workforce agility of trainees.

\section{Limitations and future research}

A first limitation of our research is that our study on the relationships with workforce agility is correlational. It is therefore difficult to draw conclusions on the direction of the relationships. One could argue that work-related curiosity, risk-taking, trust in collaborators, or job self-efficacy are prerequisite of workforce agility. However, an equally valid alternative perspective on our results could be that workforce agility fosters work-related curiosity, risk-taking, trust in collaborators, and job self-efficacy. Future research using either an experimental design or a longitudinal design could help better understanding the nature of the relationship between the eight conative traits and workforce agility. Note that future research focusing on the efficiency of training 
interventions on workforce agility - using, for example, a Randomized Controlled Trial design - could provide important information on the direction of the relationships between the conative traits identified in this research and workforce agility.

Note that our research focused on conative factors, ignoring other important psychological factors such as cognitive factors - general intelligence and creative skills -, as well as emotional factors - emotional intelligence or stress coping strategies. Indeed, it can be assumed that workforce agility being a form of adaptation (Breu et al., 2001), is influenced by cognitive capacities intrinsically related to the phenomenon of adaptation, such as creativity or intelligence. Because workforce agility involves collaborating with other individuals as part of teamwork (Breu et al., 2001), certain social relationship regulation skills such as emotional intelligence - which has been shown to contribute to adaptability at school and at work (Çelik \& Storme, 2018; Coetzee \& Harry, 2014) - could also play an important predicting role. Finally, changing environments can be considered as stressors (Wisse \& Sleebos, 2016). Therefore, it can be assumed that individuals with better stress coping strategies have more ability to adjust psychologically to changes in the

work environment and, consequently, are more agile. Future research should investigate the relative contribution of cognitive and emotional factors to workforce agility in order to provide researchers and practitioners with a more complete description of the individual resources that support workforce agility.

\section{Conclusion}

In conclusion, the present research enhances our theoretical understanding of workforce agility by introducing a series of conative antecedents of workforce agility. Our study also provides researchers and practitioners with a psychometrically sound scale - the Agility Index - to assess the individual potential for workforce agility. We hope our studies will encourage further research on the psychological antecedents of workforce agility. 


\section{References}

Alavi, S., Abd. Wahab, D., Muhamad, N., \& Arbab Shirani, B. (2014). Organic structure and organisational learning as the main antecedents of workforce agility. International Journal of Production Research, 52(21), 6273-6295.

Bandura, A. (1977). Self-efficacy: toward a unifying theory of behavioral change. Psychological Review, 84(2), 191-215. doi: 10.1037/0033-295X.84.2.191

Behrend, T. S., Sharek, D. J., Meade, A. W., \& Wiebe, E. N. (2011). The viability of crowdsourcing for survey research. Behavior Research Methods, 43(3), 800.

Berlyne, D. E. (1978). Curiosity and learning. Motivation and Emotion, 2(2), 97-175.

Boeije, H. (2002). A purposeful approach to the constant comparative method in the analysis of qualitative interviews. Quality and quantity, 36(4), 391-409. doi: 10.1023/A:1020909529486

Bowen, G. A. (2008). Naturalistic inquiry and the saturation concept: a research note. Qualitative research, 8(1), 137-152. doi: 10.1177/1468794107085301

Breu, K., Christopher, J., Strathern Hemingway, M., \& Bridger, D. (2001). Workforce agility: The new employee strategy for the knowledge economy. Journal of Information Technology, 17(1), 21-31.

Budner, S. (1962). Intolerance of ambiguity as a personality variable. Journal of personality, 30(1), 29-50. doi: 10.1111/j.1467-6494.1962.tb02303.x

Butler Jr, J. K. (1999). Trust expectations, information sharing, climate of trust, and negotiation effectiveness and efficiency. Group \& Organization Management, 24(2), $217-238$.

Çelik, P., \& Storme, M. (2018). Trait emotional intelligence predicts academic satisfaction through career adaptability. Journal of Career Assessment, 26(4), 666-677. doi: $10.1177 / 1069072717723290$

Çelik, P., Storme, M., Davila, A., \& Myszkowski, N. (2016). Work-related curiosity positively predicts worker innovation. Journal of Management Development, 35(9), 
1184-1194. doi: 10.1108/JMD-01-2016-0013

Chonko, L. B., \& Jones, E. (2005). The need for speed: Agility selling. Journal of Personal Selling and Sales Management, 25(4), 371-382.

Coetzee, M., \& Harry, N. (2014). Emotional intelligence as a predictor of employees' career adaptability. Journal of Vocational Behavior, 84(1), 90-97. doi:

10.1016/j.jvb.2013.09.001

Doeze Jager-van Vliet, S., Born, M., \& van der Molen, H. (2019). Using a portfolio-based process to develop agility among employees. Human Resource Development Quarterly, 30, 39-60. doi: 10.1002/hrdq.21337

Fuller, B., Liu, Y., Bajaba, S., Marler, L. E., \& Pratt, J. (2018). Examining how the personality, self-efficacy, and anticipatory cognitions of potential entrepreneurs shape their entrepreneurial intentions. Personality and Individual Differences, 125, 120-125. doi: 10.1016/j.paid.2018.01.005

Goldman, S., \& Nagel, R. (1993). Management, technology and agility: the emergence of a new era in manufacturing. International Journal of Technology Management, 8(1), $18-38$.

Khan, H., \& Wisner, J. D. (2019). Supply chain integration, learning, and agility: Effects on performance. Operations and Supply Chain Management, 12(1), 14-23. doi: $10.31387 /$ oscm0360218

Krueger Jr, N., \& Dickson, P. R. (1994). How believing in ourselves increases risk taking: Perceived self-efficacy and opportunity recognition. Decision Sciences, 25(3), 385-400. doi: 10.1111/j.1540-5915.1994.tb00810.x

Liu, H., Li, Z., Cai, Z., et al. (2015). The effects of task conflict and relationship conflict on workforce agility: Moderating role of social media usage. In Thirty sixth international conference on information systems.

Loewenstein, G. (1994). The psychology of curiosity: A review and reinterpretation. Psychological bulletin, 116(1), 75-98. 
Muduli, A. (2017). Workforce agility: Examining the role of organizational practices and psychological empowerment. Global Business and Organizational Excellence, 36(5), $46-56$.

Muduli, A., \& Muduli, A. (2016). Exploring the facilitators and mediators of workforce agility: An empirical study. Management Research Review, 7(1), 11-20.

Mussel, P. (2013). Introducing the construct curiosity for predicting job performance. Journal of Organizational Behavior, 34(4), 453-472.

Mussel, P., Spengler, M., Litman, J. A., \& Schuler, H. (2012). Development and validation of the german work-related curiosity scale. European Journal of Psychological Assessment, 28(2), 109-117.

Plonka, F. (1997). Developing a lean and agile work force. Human Factors and Ergonomics in Manufacturing and Service Industries, 7(1), 11-20.

Rigotti, T., Schyns, B., \& Mohr, G. (2008). A short version of the occupational self-efficacy scale: Structural and construct validity across five countries. Journal of Career Assessment, 16(2), 238-255.

Rosseel, Y. (2012). lavaan: An r package for structural equation modeling. Journal of Statistical Software, 48(2), 1-36.

Schaubroeck, J., \& Merritt, D. E. (1997). Divergent effects of job control on coping with work stressors: The key role of self-efficacy. Academy of Management Journal, 40(3), $738-754$.

Schumacker, R. E., \& Lomax, R. G. (2004). A beginner's guide to structural equation modeling. Psychology Press.

Sheffield, J., \& Lemetayer, J. (2013). Factors associated with the software development agility of successful projects. International Journal of Project Management, 31, $459-472$.

Sherer, M., Maddux, J. E., Mercandante, B., Prentice-Dunn, S., Jacobs, B., \& Rogers, R. W. (1982). The self-efficacy scale: Construction and validation. Psychological 
Reports, 51(2), 663-671.

Storme, M., \& Celik, P. (2018). Career exploration and career decision-making difficulties: The moderating role of creative self-efficacy. Journal of Career Assessment, 26(3), 445-456. doi: 10.1177/1069072717714540

Storme, M., Celik, P., \& Myszkowski, N. (2019). Career decision ambiguity tolerance and career decision-making difficulties in a french sample: The mediating role of career decision self-efficacy. Journal of Career Assessment, 27(2), 273-288. doi: $10.1177 / 1069072717748958$

Westerberg, M., Singh, J., \& Häckner, E. (1997). Does the ceo matter? an empirical study of small swedish firms operating in turbulent environments. Scandinavian Journal of Management, 13(3), 251-270. doi: 10.1016/S0956-5221(97)00011-0

Wisse, B., \& Sleebos, E. (2016). When change causes stress: Effects of self-construal and change consequences. Journal of business and psychology, 31 (2), 249-264. 
Table 1

Core dimensions of workforce agility and

their supporting resources.

\begin{tabular}{ll}
\hline Core dimension & Supporting resources \\
\hline Gathering information & - Job-related curiosity \\
& - Active listening \\
\hline Processing information & - Ambiguity tolerance \\
& - Learning from past mistakes \\
\hline Making decisions & - Anticipation and planning \\
\hline Taking action & - Job self-efficacy \\
& - Risk-taking \\
\hline
\end{tabular}


Table 2

Latent correlations with validation criteria.

\begin{tabular}{lcc}
\hline Psychological antecedent & Workforce agility (Muduli, 2017) & Workforce agility (Liu et al., 2015) \\
\hline Job-related curiosity & $.84^{* *}$ & $.80^{* *}$ \\
Active listening & $.72^{* *}$ & $.74^{* *}$ \\
Ambiguity tolerance & $.09^{*}$ & $.09^{*}$ \\
Learning from past mistakes & $.74^{* *}$ & $.79^{* *}$ \\
Anticipation and planning & $.74^{* *}$ & $.73^{* *}$ \\
Job self-efficacy & $.82^{* *}$ & $.82^{* *}$ \\
Risk-taking & $.52^{* *}$ & $.48^{* *}$ \\
Trust & $.48^{* *}$ & $.44^{* *}$ \\
\hline
\end{tabular}

Note. $N=808$.

** $p<.01 ;{ }^{*} p<.05$. 